\title{
LOURNAL.RU
}

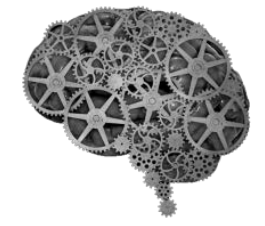

COMPANY GROUP "INTELLEKT"

\author{
Люляков И.В., Буйлов В.Н., Тарасьев Е.С. \\ Саратовский ГАУ \\ Саратов, Россия
}

doi: 10.18411/lj2016-3-62

\section{Условия работы стрельчатой лапы}

В производстве сельскохозяйственных культур почвообработка занимает значительный объем и является самой энергоемкой технологической операцией. Так, например, при производстве озимой пшеницы расход топлива на почвообрабатывающие операции составляет более $40 \%$ от общего расхода [1].

При возделывании сельскохозяйственных культур обработка почвы включает в себя следующие операции: вспашку, боронование и культивацию. Эти операции взаимосвязаны и дополняют друг друга.

Вспашка предназначена для крошения пахотного слоя на фракции, размеры которых должны соответствовать агротехническим требованиям, и выполняется по двум технологиям: отвальной и безотвальной на глубину $25 . .30$ см. Отвальную обработку осуществляют лемешно-отвальными плугами общего назначения, а безотвальную - плоскорезами-глубокорыхлителями, чезельными плугами и плугами-рыхлителями.

Боронование в основном проводится для снижения испарения влаги из почвы в весенний период и для дробления больших комков почвы, образующихся в процессе пахоты зяби и при весенней вспашке пара. Эту операцию после работы лемешно-отвальных плугов выполняют, как правило, зубовыми боронами, а при безотвальной обработке почвы - игольчатыми или дисковыми. 
Культивация выполняется в основном лаповыми культиваторами, которые предназначены для рыхления почвы и уничтожения сорняков при предпосевной обработке почвы, уходе за парами и вспашке. В зависимости от глубины обработки их подразделяют на паровые (6..12 см), культиваторы-рыхлители (до 20 см) и глубокорыхлители (до $30 \mathrm{~cm}$ ).

Паровые культиваторы применяют повсеместно, a культиваторырыхлители почти исключительно в Средней Азии, где их используют для обработки на всю толщину пахотного слоя.

Для сплошной культивации почвы применяют культиваторы КПГ-4, КПС4, КП-4М и КПН-4Г с однотипными рабочими органами - полольными стрельчатыми лапами (ОСТ 23. 2164-87), ширина захвата которых - 270 и 330 мм (рис.1).

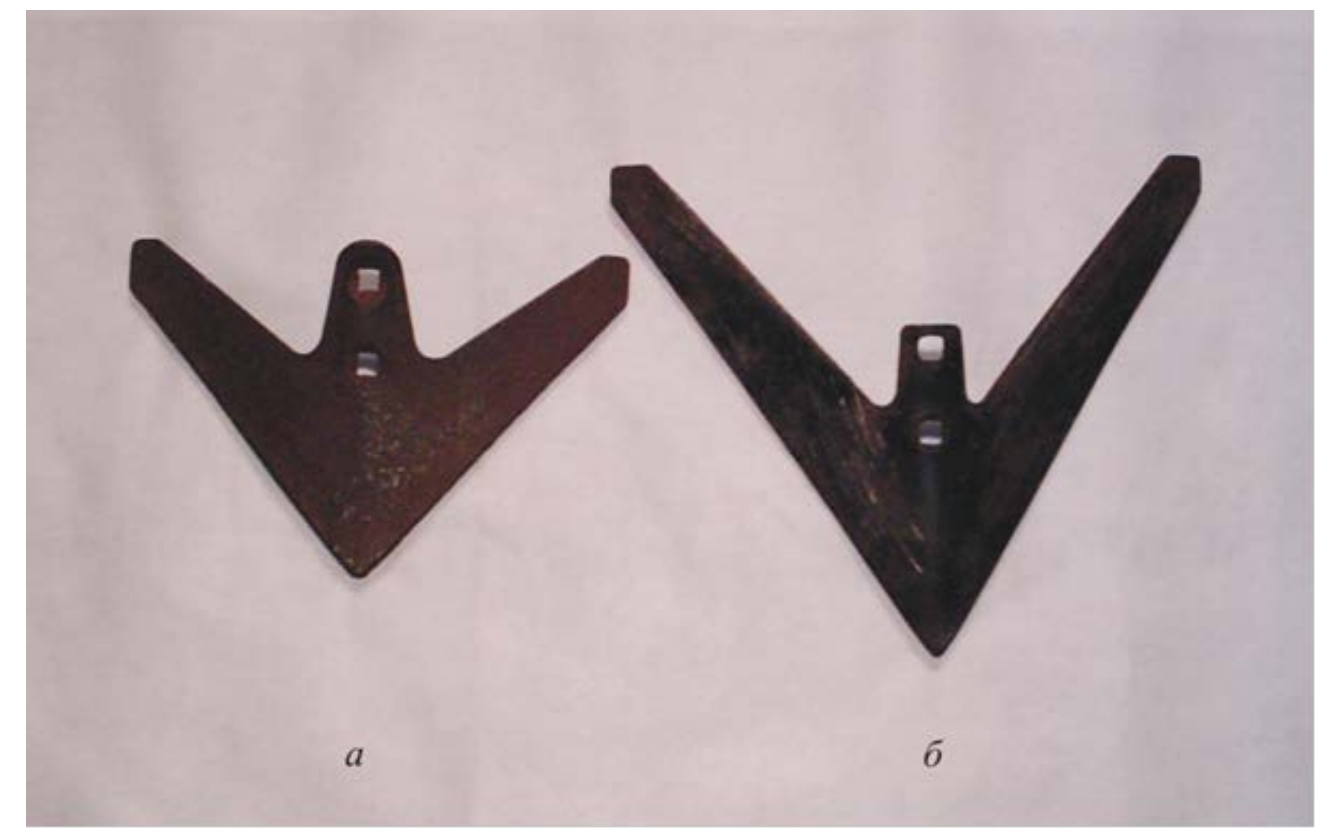

Рис.1. Серийные культиваторные лапы: а - ширина захвата 270 мм; б - ширина захвата 330 мм

При некачественной культивации теряют всхожесть до половины высеваемых семян, а взошедшие созревают неравномерно [1-3]. Тяговое сопротивление увеличивается более чем на $50 \%$ у культиваторов с затупленными лапами [1]. При неравномерности глубины обработки, которая зависит от технического состояния культиваторных лап, засоренность полей возрастает на $30 \%$, урожайность пшеницы снижается на 18 , ячменя - на 
12, гречихи - на 13, овса - на 4 \%, а также ухудшается качество зерна [1].

На необходимость повышения износостойкости режущих органов сельскохозяйственных машин указывали в своих работах академики В.П. Горячкин, В.А. Желиговский и другие ученые [1-3].

Как известно, стрельчатая лапа состоит из носовой части 1 (рис. 2), двух крыльев 2 и хвостовика 3. Размеры и форма лап характеризуется углами раствора $2 \gamma$, крошения $\beta$ и шириной захвата $b$, а также шириной в начале $b 1$ и в конце b2 крыла. Угол $\gamma$ должен быть таким, чтобы подрезание сорняков производилось скользящим резанием, а корни вырванных сорняков безостановочно скользили вдоль лезвия. При невыполнении этого условия происходит так называемое явление «обволакивания лезвия» (срезанные стебли скапливаются на крыльях лап), в результате чего прекращается подрезание сорняков с одновременным стремлением к выглублению из почвы. Степень производимого рыхления почвы определяется величиной угла крошения $\beta$. В зависимости от его величины лапы подразделяются на плоскорезные $(\beta=$ $\left.12 \ldots 18^{\circ}\right)$ и универсальные $\left(\beta=25 \ldots 30^{\circ}\right)$. Ширину крыла обычно делают уменьшающейся к концу; минимальный размер b2 составляет $30 \ldots 50$ мм, а максимальный b1 - соответственно $45 \ldots 75$ мм. Толщину материала $\delta$ для лапы выбирают в зависимости от ширины захвата, ширины крыла, глубины обработки, свойств почв и механических свойств выбранной марки стали. Для ориентировочного выбора $\delta$ можно пользоваться эмпирическими зависимостями: $\delta \leq 0,02 \mathrm{~b}$ - для культиваторов, предназначенных для сплошной обработки почвы, и $\delta \leq 0,03 b$ - для культиваторов-рыхлителей [1-3].

Заточка лезвия может быть верхней, нижней и комбинированной (рис. 3). Выбор типа заточки не может быть произвольным. Для обеспечения устойчивости хода по глубине задний угол резания лезвия $\varepsilon$ должен быть больше либо равен $10^{\circ}$. Угол заострения і не должен быть меньше $12 \ldots 15^{\circ}$. Поэтому, если $\beta<15^{\circ}$, заточка лезвия должна быть верхней (рис. 3 , а), при $\beta$ 
$>25^{\circ}$ - нижней (рис. 3, б) и при $15^{\circ}<\beta<25^{\circ}-$ комбинированной (рис. 3, в). Для обеспечения хорошего подрезания сорняков радиус режущей кромки лезвия после заточки должен быть не более 0,3 мм.
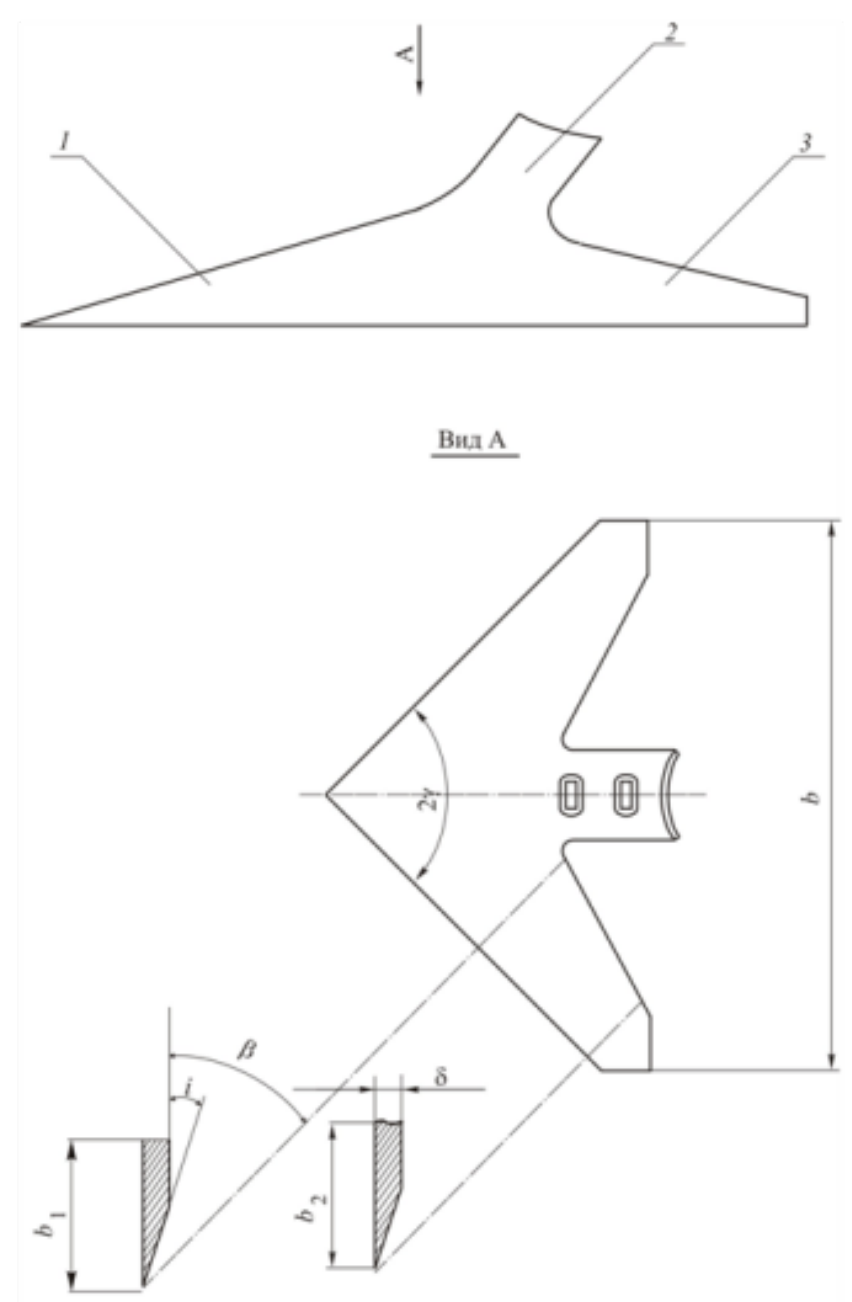

Рис. 2. Схема стрельчатой лапы с хвостовиком: 1 - носовая часть лапы; 2 - крыло; 3 - хвостовик

Основным материалом, применяемым для изготовления лап культиваторов, служит марганцовистая сталь марки 65Г, ГОСТ 1050-88 см. табл. 1 и 2.

Таблица 1 - Химический состав стали 65Г

\begin{tabular}{|c|c|c|c|c|}
\hline \multicolumn{5}{|c|}{ Химический состав, \% } \\
\hline Углерод & Марганец & Кремний & Хром & Железо \\
\hline 0,66 & 1,1 & 0,27 & $<0,25$ & Остальное \\
\hline
\end{tabular}




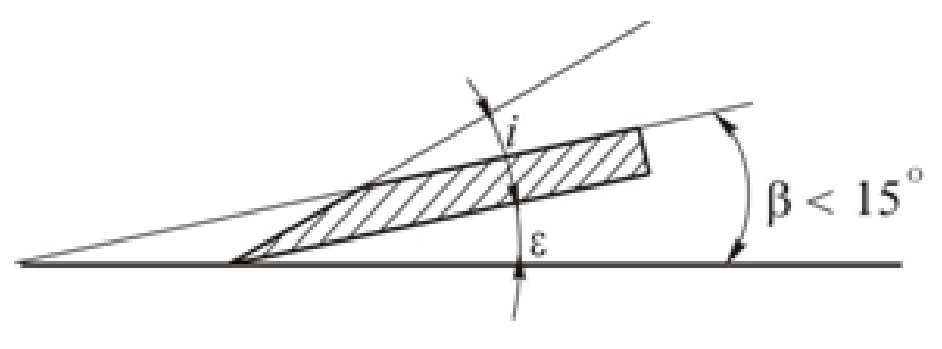

$a$

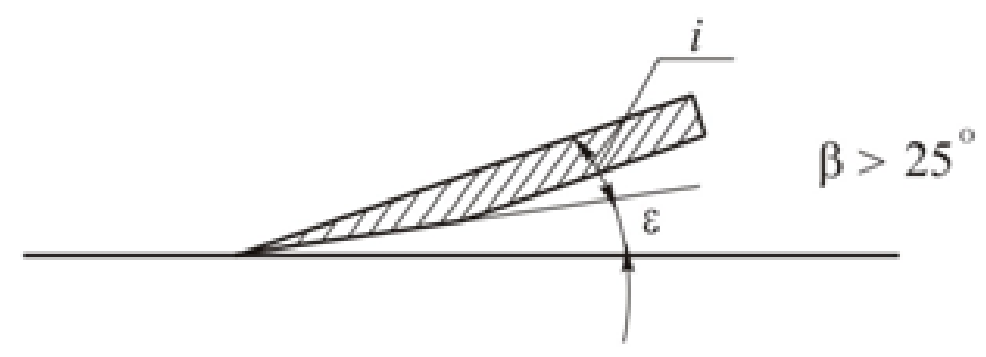

$\sigma$

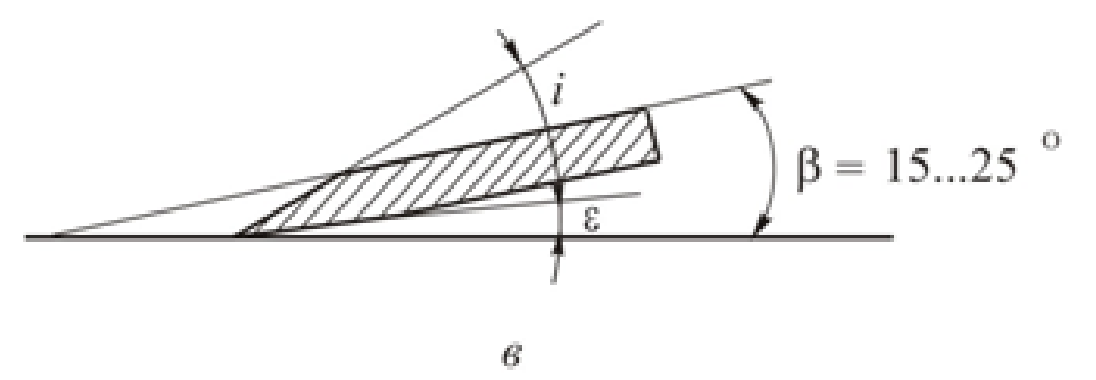

Рис. 3. Способы заточки лезвия лапы:

а - верхняя; б - нижняя; в - комбинированная

Технология изготовления лап включает в себя следующие операции: вырубка заготовки; фрезерование лезвия; пробивка отверстий; горячая штамповка лапы; заточка; закалка лезвия при температуре $810 \ldots 830{ }^{\circ} \mathrm{C}$; отпуск при температуре $450 \ldots 480{ }^{\circ} \mathrm{C}$. Твердость режущей части (шириной $25 \ldots 40$ мм) полольных лап должна быть HRC44...HRC54, а остальная часть допускается не более HRC44 [1-3].

Для придания полольным лапам способности самозатачиваться во время работы их лезвия делают двухслойными (рис. 4) путем наплавки на основной материал с тыльной стороны износостойкого сплава толщиной 0,3...0,5 мм, например сормайта см. табл. 3. 
Самозатачивание двухслойного лезвия осуществляется вследствие более быстрого изнашивания основного материала и выступания из-под него наплавленного слоя. Твердость наплавленного сормайтом слоя составляет HRC49...HRC55.

Таблица 2- Механические свойства стали 65Г после термической обработки

\begin{tabular}{|c|c|c|c|c|c|c|c|}
\hline \multicolumn{3}{|c|}{ Режимы термической обработки } & \multicolumn{5}{|c|}{ Механические свойства } \\
\hline 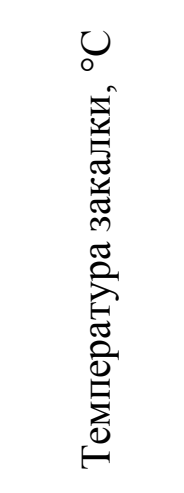 & 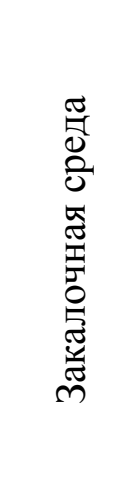 & 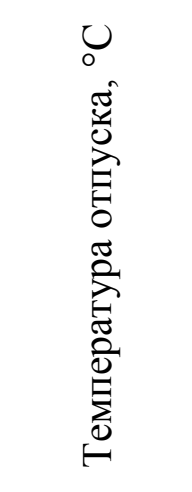 &  &  & 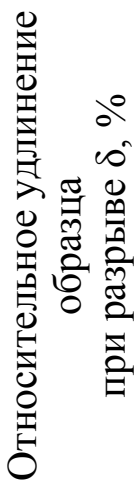 & 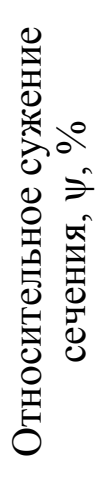 & 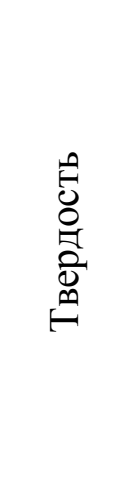 \\
\hline \multirow[b]{2}{*}{$810 \ldots 830$} & \multirow[b]{2}{*}{ Масло } & $530 \ldots 600$ & \multirow[b]{2}{*}{$880 \ldots 1030$} & \multirow[b]{2}{*}{680} & \multirow[b]{2}{*}{8} & \multirow[b]{2}{*}{34} & \multirow{2}{*}{$\begin{array}{c}\text { HRC44 } \\
\ldots \\
\text { HRC54 }\end{array}$} \\
\hline & & $450 \ldots 480$ & & & & & \\
\hline
\end{tabular}

Таблица 3 - Химический состав сормайта, \%

\begin{tabular}{|c|c|c|c|c|c|}
\hline Углерод & Марганец & Кремний & Хром & Никель & Железо \\
\hline $2,5 \ldots 3,5$ & $0,5 \ldots 1,5$ & $2,8 \ldots 4,2$ & $25 \ldots 31$ & $3,0 \ldots 5,0$ & Остальное \\
\hline
\end{tabular}

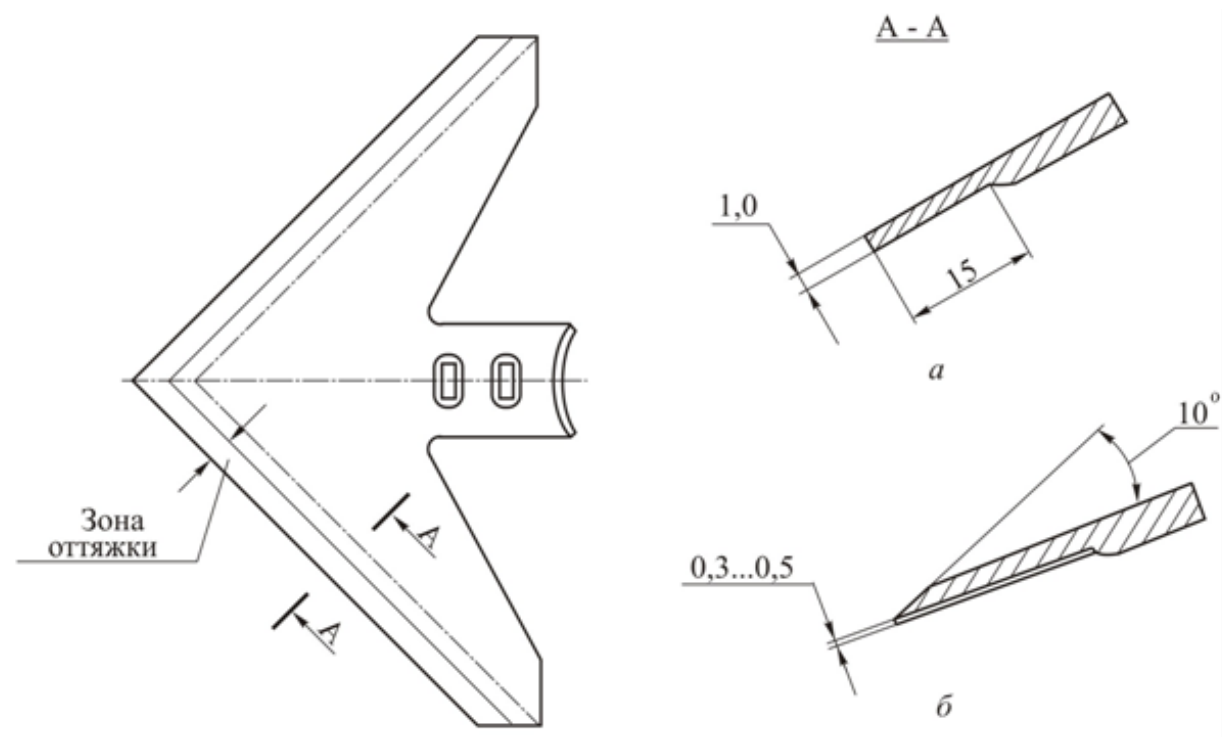

Рис. 4. Наплавка полольных лап твердым сплавом: а - после оттяжки; б - после наплавки и заточки 
Следует отметить, что в настоящее время цена листового проката из стали марки 65Г в 1,8 - 2 раза выше, чем из сталей марок 20 и 30. Технологический процесс изготовления лап культиваторов, включающий в себя термообработку режущих кромок, не обеспечивает увеличения срока их службы, так как при последующей наплавке износостойкого сплава сормайт происходит разупрочнение режущих кромок вследствие отпуска. Механическая прочность наплавленного слоя недостаточна, из-за чего происходит разрушение режущей части.

\section{Литература:}

1. Люляков, И.В. Разработка технологии восстановления стрельчатых лап культиваторов путем замены режущей части / И.В. Люляков / автореферат диссертации на соискание ученой степени кандидата технических наук / Саратовский государственный аграрный университет им. Н.И. Вавилова. Саратов, 2005

2. Люляков, И.В. Способ восстановления лап культиваторов почвообрабатывающих машин / В.Н. Буйлов, И.В. Люляков, Н.П. Волосевич, В.М. Бойков, С.А Пронин./Патент на изобретение RUS 2325256 27.03.2006

3. Люляков, И.В. Моделирование процесса электроискрового наращивания изношенных поверхностей / В.Н. Буйлов, И.В. Люляков, В.С. Еременко / Аграрный научный журнал. 2013. № 8. С. 47-50. 